\title{
MULTIVOCIDAD DE LA VIOLENCIA
}

\author{
Juliana González Valenzuela
}

Facultad de Filosofia y Letras

Universtoad Nactonal Autónoma de México

De la Gorgona brotan dos gotas de sangre, según Eurípides: una de ellas, "aleja las enfermedades, aumenta el valor... y alimenta la vida humana..."; la otra, en cambio, "mata; es el veneno de las serpientes..." $1 \mathrm{Y}$ sobre esto comenta René Girard:

Nada más diferente que estas dos gotas de sangre y, sin embargo, nada más semejante. Es fácil por consiguiente, $\mathrm{y}$ tal vez tentador, confundir las dos sangres y mezclarlas. Si se produce esta mezcla desaparece cualquier distinción entre lo puro y lo impuro. Ya no hay diferencia entre la buena y la mala violencia. En efecto, mientras lo puro y lo impuro permanecen diferenciados, es posible lavar hasta las mayores manchas. Una vez que se han confundido, ya no se puede purificar nada. ${ }^{2}$

La sabiduría del mito o de la poesía, recae ciertamente en el carácter contradictorio, ambivalente, multívoco en general, de los fenómenos humanos: la imposibilidad de pensar en hechos o acciones que se puedan definir de una sola manera simple y pura, con caracteristicas absolutamente positivas o negativas. Así como el amor - según veía Platónno es, en sí, siempre "bueno" o un "dios", sino que puede haber "buen amor" o "mal amor", así también parece que hay "buena violencia" y "mala violencia" y que es enorme, en efecto, la tentación de confundirlas, a la vez que es inmensa la dificultad y la urgencia de diferenciarlas.

Pocos fenómenos son, en efecto, tan ambiguos, movedizos, variados y contradictorios - tan llenos de problemas y aporías - como el de la violencia; y pocos tan necesitados - sobre todo en nuestro tiempo- de una clara separación y distinción de sus funciones de vida o de muerte (como las gotas de sangre de la Gorgona).

¿Cuál es la "buena" violencia y la "mala" violencia? ¿Existe en rea-

I Eurfpides, Ion, 991-1028. La misma función ambivalente la tenía el phd́rmakos griego.

2 René Girard, La violencia y lo sagrado. Ed. Anagrama, Barcelona, 1989. 
lidad una "buena" violencia? ¿O más bien no seria ni buena ni mala, sino mera "estrategia" técnica o "cientiffica", descualificada e indiferente, regida por la mera necesidad? ¿Y si es cualificable, cuáles serían los criterios de validez para distinguirla? ¿Cómo trascender en general los distintos relativismos (e "indiferentismos") partiendo del hecho irrebasable de la relatividad, de los dobleces y de la movilidad de lo existente? Porque es claro que no puede haber criterios que proporcionen seguridades absolutas, diferencias puras, univocas y tajantes; que el mundo de las acciones y valoraciones está siempre sujeto a interpretación, a discusión, a rectificación, a mera probabilidad y a una necesidad continua de deliberación, de crítica y discernimiento, sin vencer jamás el riesgo y la inseguridad. Y no obstante, parece que tiene que haber criterios o principios generales que ofrezcan alguna pauta válida de diferenciación y de valoración, por meramente indicativa y, también, perfectible, que ésta sea. ${ }^{3}$

La violencia es ella misma "Fuerza"; vis [en latín], Bias [en griego]: energía vital, vigor, poder o potencia; la fuerza remite también a la dynamis griega: la potencialidad en todos sus sentidos. La violencia es fuerza y poder, en efecto, pero no toda fuerza o poder es violencia. La Bias o Violentia es una clase de fuerza: la fuerza indómita que se impone contra una resistencia, contra una voluntad, contrariando o "forzando" la naturaleza de aquello sobre lo cual recae o se ejerce: avasallando, obligando, violentando o violando.

Hay en cambio otras clases de fuerzas: la vis de la virtus, de la virtud, que es fuerza y fortaleza humana, distinta y hasta generalmente opuesta a la violencia. También la vis o la dynamis del arte, de la póiesis y de la praxis: la fuerza de la creación, de la producción, del

3 No se pretende aqul sino aludir a algunos -y sólo algunos- de los sentidos diversos [positivos y negativos] en que se entiende la violencia, e intentar, asimismo, una aproximación (desde un enfoque ético) tanto al problema de los criterios de cualificación moral de la violencia, como al del carácter "natural" o constitutivo de la violencia humana (de la violencia como destructividad o agresividad), poniendo de relieve muchas de las dificultades que se suscitan en torno. Se mantiene asi, por una parte, el uso amplio y general de 'violencia' destacando justamente sus ambigüedades y contradicciones, de modo que quedan comprendidas, tanto la violencia como fuerza de vida, como de muerte; tanto la que se ejerce sobre lo humano, como sobre la naturaleza en general; lo mismo la violencia "física", directa, consciente e intencional, que la violencia psicológica o moral, o social, que puede ser también indirecta y hasta inconsciente e involuntaria; tanto la violencia individual o personal, comó la colectiva e institucionalizada. No obstante, se apuntan también, por otra parte, algunas notas definitorias o especificas de la violencia en cuanto tal -aunque su formulación no sea exhaustiva ni definitiva_, a la vez que se procura precisar un sentido restringido de la violencia como fenómeno intrinseca y éticamente negativo, que sólo puede adquirir una eventual significación positiva en cuanto medida estrictamente de excepción y dentro de un contexto axiológico mayor que la justifique. 
trabajo humano. O bien la fuerza del logos mismo, de la palabra, de las razones. $\mathrm{Y}$ también la fuerza del eros y de la philia. E incluso la fuerza o la vis de la no-violencia, de la paz y la pacificación, de las fuerzas humanas de conciliación, de espera, de respeto, de tolerancia, de recepción y de escucha: las fuerzas nocturnas, silentes, de la intimidad, de lo receptivo, que contribuyen por igual a la actividad y al movimiento de todo lo que es. Hay distintas clases de fuerzas o potencias, en general, una de las cuales, y sólo una, es la violencia, cuya especificidad se centra en ser fuerza extrema, impetuosa, de oposición, de transgresión o de destrucción, avasalladora y dominante.

A diferencia de otras fuerzas o manifestaciones de fuerza en general, la violencia se distingue, entonces: a) por su intensidad, su energfa y rudeza extremas; b) por su carácter súbito, inmediato, intempestivo; c) por el cambio brusco que genera; d) por el tipo de encuentro entre distintas fuerzas o distintas naturalezas que conlleva: un encuentro que es choque, contraste intenso, lucha, confrontación o guerra; e) por su indole frecuentemente destructiva o al menos coercitiva y.dominante; f) por el des-orden o quebranto de un orden establecido (desorden real o aparente, momentáneo o permanente) que suele implicar.

Pero hay también distintas clases de violencia y distintos modos de interpretar y de valorar el hecho.

Asl por ejemplo, atendiendo al significado de fuerza, energia, potencia en general, la violencia ha sido destacada [19] como un poder esencialmente positivo. Es paradigmático, sin duda, el sentido que la violencia adquiere, por ejemplo en la revolución axiológica de Nietzsche, donde incluso llega a identificarse con la virtud misma, en tanto que las nuevas virtudes propuestas por Nietzsche (en contra de la nihilista negación de la vida, fruto de la debilidad y el resentimiento) responden al "sentido de la Tierra"; son fuerza implacable, impetu avasallador, explosión de, la vitalidad, voluntad de poder, con todo lo que ésta implica en el contexto nietzscheano: moral de "señores" frente a moral de "esclavos".

$\mathrm{Y}$ es notable también - por no citar sino dos de los casos más destacados de apologias de la violencia, hechas desde campos y orientaciones diferentes - la famosa defensa de la violencia política efectuada por George Sorel. Para éste, ciertamente, como glosa Berlin:

La violencia es la destrucción de las cadenas, el preludio de la regeneración... la renovación de la vida, el rejuvenecimiento, la liberación de los poderes creadores... todo esto no es posible lograrlo. mediante la persuasión, sin recurrir a la violencia como arma de la libertad...4

- Isaiah Berlin, Prefacio a la obra de George Sorel, Reflexiones sobre la violencia. 
Pero es muy significativo que también Sorel se empeña en distinguir tajantemente una "buena" de una "mala violencia", aunque designando la positiva precisamente con el concepto de "violencia" y con el de "fuerza" a la negativa. Así, la "violencia" es buena por ser potencia liberadora y creadora, mientras que la "fuerza", según él, impone cadenas, esclaviza, es opresora y fuente de toda dictadura y explotación. De ahí que la "violencia", para no convertirse en "fuerza" -en los términos de Sorel_-, para no pasar ella misma a la opresión que trata de superar, debe mantenerse en lucha heroica, sin victoria, sin generar en su poderfo una nueva dominación o una nueva "dictadura".

En general, ya se conciba a la manera de Nietzsche o de Sorel (e independientemente de ellos), como expresión de la fuerza vital, de la afirmación expansiva del propio ser, o bien como poder liberador, emancipador, revolucionario, parece evidente que la violencia tiene aquí el carácter de "buena violencia", de un bien positivo; tiene, por un lado, un sentido opuesto a los males que representan el empobrecimiento y mengua de la vida, la cobardia y la debilidad, y por el otro, uno contrario a toda forma de sometimiento, de aceptación pasiva de la opresión o de sumisión malsana a la otra violencia de que somos víctimas.

Pero es necesario recaer en esta colindancia $\tan$ estrecha o este deslizamiento tan fácil que parece haber entre la violencia positiva y la negativa, entre la gota de sangre que es vida y la otra gota que es veneno mortal. Lo decisivo es que la violencia, vista como este poder afirmativo de vitalidad y liberación, está siempre extremadamente próxima a las significaciones y poderes contrarios.

Como bien supieron los griegos, la violencia [29] es hybris: exceso, desmesura, exuberancia, soberbia, desproporción, ruptura de todo límite; es la fuerza desenfrenada, el poder desmedido, desbordado, arrollador, que invade y destruye cuanto toca; la hybris se dice primitivamente del animal descarriado o de las fuerzas indómitas, desatadas o des-encadenadas de la Naturaleza: el torrente, el fuego, el diluvio, el terremoto. Aunque en sentido estricto, sólo cabe hablar de hybris en el hombre; sólo éste "rebasa las medidas" porque sólo el hombre no tiene unos límites fijos, uniformes, preestablecidos para su existencia; sólo el hombre es el gran transgresor e infractor, capaz de dar contra-orden, capaz de cometer "violencia". Como veían los estoicos, la pasión humana es en última instancia exceso, exageración del deseo o del temor (o del poder). Por eso, lo contrario de la hybris, de la desmesura o de la in-temperancia, es la sofrosyne: la templanza, el temple; la violencia es des-templada, es abu-

Alianza ed., Madrid, 1976, p. 42. Cf. asimismo, Jorge Pinto M., Sorel, ed. Edicol, México, 1978. 
so de fuerza y de poder. O como lo expresa Jaeger, a propósito de la concepción griega de la hybris y, a su vez, el propio Solón:

El peligro demoníaco [la hybris] se halla en la insaciabilidad del apetito, que siempre desea doble de lo que tiene, por mucho que esto sea.

La saciedad conduce a la hybris y la hybris a la ruina.

La violencia, entonces, lejos de ser el poder de vida y liberador, pasa a ser la fuerza misma de la opresión y la dominación, de los impedimentos, los frenos y los controles. $\mathrm{Y}$ es evidente que no es lo mismo poder o potencia que "dominio", poder que mero "poderío". Pues del otro lado de la moneda está, no el sujeto de la violencia (sujeto individual o colectivo) que se afirma o se libera por la violencia, sino el objeto sobre el cual recae la acción violenta: aquello o aquel contra el cual ejerce la fuerza; importa ahora lo que pasa con este algo o alguien que recibe la violencia. Pues no es igual la violencia que se ejerce sobre una fuerza o resistencia igual o mayor, que la que se ejerce sobre el débil, el indefenso, el desvalido; no es lo mismo la lucha que la crueldad y el terror; no es igual la violencia que conquista, transforma, vence incluso, que la violencia que debilita, ultraja, desvalora; que no deja ser al otro, que lo explota y hasta lo extermina: la violencia como 'violación', en suma. [39]

Los excesos de la afirmación, del "si", pasan a ser los horrores del "no", de la coerción y la represión; de la prohibición y la ley. [49] Una de las modalidades más significativas es evidentemente la violencia "legalizada", autorizada por el poder, por la fuerza del fuerte o del poderoso. La violencia de "cruzadas", "inquisiciones", "purgas" de toda indole. Violencia "justa" y "justificada", amparada en el Derecho y la Ley; la violencia impune, sacralizada de La Justicia, la venganza pública, destinada a "vigilar y castigar", desde las modalidades abiertas de la desnuda brutalidad física, hasta los sublimados métodos "no corporales" de la violencia "jurídica" o institucional. ¿Cuándo la violencia de "la justicia" es violencia "justa", o al menos necesaria y cuándo simple violencia maligna pero enmascarada, más maligna aún por su hipocresía, su apariencia de acto noble, inevitable y plenamente justificado? $¿$ Cabe en realidad una violencia justa? ${ }^{\circ}$

Paradójicamente, por lo demás, la violencia no es siempre signo de

5 Werner Jaeger, Paideia, F.C.E., México, 1962, p. 238.

6 Cf., entre otras obras: Walter Benjamin, Para una critica de la violencia, Premiá ed., México, 1977. Y Michel Foucault, Vigilar y castigar, nacimiento de la prision, Siglo XXI, México, 1976. 
poder - ya sea poder de vida o de muerte- sino que suele ser, en sus manifestaciones más frecuentes, signo de impotencia radical [59]: no exceso de vitalidad y de fuerza sino originariamente fracaso, frustración de todo lo vital, debilidad y defecto, que se quieren compensar por el afán de dominio y poderío. De ahí la violencia del resentimiento, la venganza, el sadismo, tanto en el orden sexual como en el de la crueldad en general:

Incluso la violencia puede ser resultado de aburrimiento, de la indolencia y de la falta de creatividad: expresión de esterilidad y vacío interiores, de necesidad de estímulos (violentos) para percibir, para sentir, para vivir. Contrariamente a la buena violencia, signo de fuerza vital, la violencia en este caso es justamente expresión de insensibilidad.?

Asimismo, otra variante de impotencia es la violencia como brutalidad [69] (infantil o primitiva, o simplemente patológica) que no cuenta con otras vías de poder o de fuerza que la agresión y la destructividad; el mero impulso visceral; la cólera, la furia, la demanda apremiante, incontrolable, compulsiva, que busca inmediata satisfacción de las necesidades; el ciego impulso de placer, egocéntrico, tan irracional como irreal, que no admite dilaciones ni espera, ni tiene conciencia temporal; la violencia es prisa, falta de tiempo... y de espacio, carencia de distancias, de perspectiva y reposo: es esencial ceguera, impaciencia y desesperación: cúmulo de fracasos; es, en realidad, expresión de debilidad, dependencia y miedo, lo mismo en el orden individual que en el colectivo o social.

Lejos de consistir, entonces, en una manifestación de la libertad, la violencia en estos sentidos de constricción e impotencia está más bien próxima al orden de la necesidad. Ésta es, en efecto, otra de sus expresiones más frecuentes: la violencia como forzosidad [7\%], como "mal necesario", inevitable, impelido, tanto en sus funciones defensivas como en las agresivas, destinadas a la sobrevivencia o a la conservación de la vida. Se trata ahora de la violencia como fuerza de agresividad, común al hombre y a la vida animal. Y éste sí sería un orden prácticamente descualificado, neutral, pero que por ello mismo remite a los estadios pre-humanizados cercanos a la naturaleza meramente biológica o física. $\mathrm{La}$ violencia como cuestión de "fuerza mayor", reactiva, compulsiva, mera respuesta refleja, tan "neutral" y "fatal", tan "necesaria" como cualquier fenómeno natural.

Un caso distinto, de índole especial, es el de la violencia interior [ $8^{\circ}$ ], intrapsíquica, destacada por Freud cuando descubre el fenómeno de represión, meollo del psiquismo inconsciente, o el de esa instancia moral

₹Vid Gilbert Torjman, La violencia, el sexo y el amor, Ed. Gedisa, Barcelona, 1981. 
profunda que conceptúa como superyó y que consiste, según él, en una especie de juez o verdugo interior que, desde el trasfondo oculto del alma, ejerce su doble función de violencia: culpa y castigo, por un lado, tortura y exigencias perfeccionistas, por el otro: hacernos sentir culpables por lo que "no debemos ser", o bien inferiores por lo que "debemos ser" y no somos, y nunca llegaremos a ser. Violencia moral, fuente de enfermedad o de un "malestar" insuperable.

Aunque Freud reconoce también la imposibilidad de quitar los diques morales cuando recae en la otra violencia, opuesta a la de la moral y la cultura: la violencia de la propia naturaleza humana. Ésta no sólo es para Freud el egoista y regresivo universo regido por una libido incestuoso-parricida, sino también por la crueldad, el odio, la destructividad, las pulsiones de muerte o desintegración. Freud da cuenta, en efecto, de esas dos caras principales de la violencia: la opresión moral y la hybris natural, entre las cuales se halla acosado el hombre, el cual no se libera de la violencia de la cultura retornando a la violencia de la natura. De ahí que parezca que la única solución real se cifre -en términos marcusianos- en una superación de la represión "sobrante", pero no de toda represión, freno o prohibición. ${ }^{8}$

"Si tu mano derecha te ofende, córtatela y arrójala lejos de ti" - declara el Evangelio.

Cabe decir, en efecto, que no hay vida moral ni vida política, ni histórica (no hay de hecho movimiento, creación, transformación), sin hacernos y hacer violencia: sin contrariar a la naturaleza: sin destrucción, renunciación y sufrimiento. No sólo la acción moral, sino la acción libre en general, conlleva necesariamente cortes, negaciones, frenos, prohibiciones, sacrificio en el sentido más amplio del término: implica opción, y ésta, renuncia: elección de una alternativa y cancelación de otras.

Son muy significativos, así, los análisis de René Girard sobre el papel que juega la violencia en el fenómeno religioso [99]. La religión, cifrada principalmente en el ritual de sacrificio ( $y$ en la existencia, por tanto, de una víctima sacrificial) se centra en un acto de violencia - que va desde el sacrificio humano hasta el sacrificio simbólico- destinado paradójicamente a prevenir la violencia, a proteger a la comunidad de una violencia mayor. El sacrificio es violencia contra la violencia. Así, dice Girard:

8 Cf. nuestro libro El malestar en la moral [Freud y la crisis de la ética], Ed. Planeta-J. Mortiz (en prensa). 
Los comportamientos religiosos y morales apuntan a la no-violencia de manera inmediata en la vida cotidiana, y de manera mediata frecuentemente en la vida ritual, por el intermediario paradójico de la violencia... ${ }^{\circ}$

...todos los procedimientos que permiten a los hombres moderar su violencia son análogos en tanto que ninguno de ellos es ajeno a la violencia. ${ }^{10}$

...no se puede prescindir de la violencia para acabar con la violencia. ${ }^{11}$

...la violencia fundadora constituye realmente el origen de cuanto poseen de más precioso los hombres. ${ }^{12}$

Sin embargo, la idea de una "violencia fundadora" o de una violencia necesaria, neutral o "buena" nos vuelve a los mismos problemas cruciales planteados al principio, ¿qué distingue a esta "violencia fundadora" de índole positiva, de la "mala violencia" que se supone que combate? ¿Qué diferencia hay entre esta violencia que se juzga tan valiosa y todas las otras violencias "justificadas" y "justas" (santificadas por la justicia humana o divina) que recién se ponían en cuestión?

Parece que es inevitable seguirse preguntando: ¿Cuál es la justificación moral de la violencia? ¿La tiene? ¿Cuál violencia? $Y$ respecto al problema de la represión y de la necesidad ética de negación y renuncia, ¿hasta dónde es "sobrante" la represión? ¿Qué distingue una moral de crueldad y enfermedad, de una moral sana y vital? ¿Cuándo la negación (y con ella la violencia) afirma y "funda" una mejor realidad y cuándo simplemente niega, anula y aniquila? ¿Son acaso suficientes los criterios del "mal menor" y el del "fin que justifica los medios"? ¿Pero cómo prescindir entonces de la conciencia kantiana de que el hombre es fin en sí mismo y jamás puede legítimamente servir de medio? ¿O cómo dejar de lado, asimismo, aquel clamor dostoyevskiano de que ningún fin, por noble y bondadoso que sea, justifica el sufrimiento de inocentes; de que ningún futuro perfecto (de armonía y conciliación beatíficas del "león y el cordero reconciliados") explica siquiera la existencia en el presente del odio del hombre contra el hombre? ¿Resulta moralmente admisible la propuesta de Sartre, de que "ganaremos el derecho a amar derramando sangre"? Y si no, ¿cómo explicar la existencia de una violencia "positiva" o al menos "necesaria"?

Justificable o no, parece cierto, por lo pronto, que hay una violencia que es relativa y relativizada, mediada y equilibrada por la existencia

9 R. Girard, op. cit., p. 28.

10 tdem., p. 30.

11 tdem., p. 33.

12 Idem., p. 101. 
de fuerzas opuestas: limitada y circunscrita a un ámbito especial, restringido; incluida como parte de un todo mayor o un contexto vital general que le otorga un sentido y una función distintos de ella misma, esenciamente no violentos (por ejemplo, la que se mantiene bajo control religioso, ritualizada, alejada por su sacralidad, cuidadosamente tratada). Sobre todo, es la violencia que se da como último recurso, extremo, necesariamente parcial, contingente, limitado en su propia extensión y duración, que se ejerce cuando parece no haber otra alternativa; ${ }^{13}$ que es medida de excepción y, en todo caso, consciente de si misma, cualificada en su riesgo y su peligro, incluso en su capacidad y significación negativas; la violencia que se sabe como tal y que sabe, asimismo, cuán relativa, limitada y precaria es su propia justificación. ${ }^{14}$

Otra muy distinta es, por el contrario, la violencia que es la hybris en cuanto tal, porque tiende a la totalización, porque implica un desencadenamiento y una "reacción en cadena" sin límites; la violencia esencialmente gratuita, absolutizada, sin nada que la detenga ni contenga, ni la equilibre; invasora, irracional, destructora; que propende consciente o inconscientemente a hacerse fin en sí misma y que no descubre sus motivaciones verdaderas, sino que se emboza y enmascara y se ostenta, además, plenamente autorizada y racionalizada.

Caso extremo de esta clase de violencia es el que se produce en el mundo contemporáneo [10\%], cuando precisamente la violencia tiende a dejar de ser el último recurso, anómalo y pasajero, y se torna el único, la apelación más generalizada, constante, uniforme, ubicua, permanente: la violencia como costumbre universal, continua y colectiva, normalizada, que penetra en todos los estadios y niveles de la vida, sin que cause ningún asombro moral. Nuestro tiempo, dice Eduardo Nicol, ha generado

... una verdadera cultura de la violencia y el odio... La violencia forma cultura cuando todo está destemplado; cuando deja de ser incidente y se convierte en una predisposición; cuando invade territorios de la existencia que son por naturaleza apacibles; cuando se

13 Vid, José Ferrater Mora y Priscilla Cohn, Ética aplicada, del aborto a la violencia, Alianza ed., Madrid, 1981. Según Ferrater la violencia sólo es justificable, " $y$ aun con muchos considerandos, cuando constituye una respuesta sin otra alternativa a una situación en la cual se violan sistemáticamente... derechos humanos básicos... apostar en favor de la no violencia es siempre preferible a apostar en favor de la violencia" (p. 203) .

$14 \mathrm{El}$ acto de violencia - como cualquier acto posible- en efecto, no adquiere su significación y su valor concreto desconectado de su contexto cabal, interno y externo (psicológico, histórico, social, axiológico, cultural). Varían las intenciones, las finalidades, las situaciones en general y con tales variaciones cambia la cualidad misma, el sentido esencial de los actos. 
preconiza como el único procedimiento eficaz; cuando, en suma, la eficacia se adopta como razón suprema. ${ }^{15}$

La "frialdad" de la guerra contemporánea se traduce no sólo en ese péndulo constante que cae sobre el futuro humano (cada vez más presente), sino además en esa filtración o invasión total del estado de guerra, de odio, ruptura y desesperación que impide cualquier comunicación interhumana, que penetra incluso en la intra-subjetividad, en el interior de cada uno, poniéndonos en guerra con nosotros mismos. Violencia como modo universal de existencia: política, moral, sexual, psicológica, "deportiva", intelectual y verbal.

¿Será acaso que la violencia - de odio, de agresión de todos contra todos y contra todo-, es en realidad nuestra condición profunda y verdadera, la esencia misma de la historia; no una situación temporal, contingente y superable, sino nuestro ser mismo, nuestra condición ontológica, como ha establecido, por ejemplo, J. P. Sartre?

Es cierto que, precisamente en el orden ontológico, el pensamiento dialéctico ve en la violencia [11\%] algo inherente y necesario al proceso mismo: el devenir, el cambio de todo cuanto es, conlleva la lucha (Pólemos la llamó Heráclito), la oposición, la escisión, la negación y también lo que Hegel conceptuó como "el trabajo de lo negativo". Más concretamente aún: para éste, como es bien sabido, el reconocimiento de la intersubjetividad humana se da en una "lucha de vida o muerte" y en una "dialéctica de amo y esclavo" caracterizada esencialmente por la oposición y la violencia absolutas. Claro está que para Hegel tras la violencia se produce el "perdón" y la reconciliación armónica, incluso la sintesis final de la unificación absoluta (que es motor teleológico del mismo proceso), de modo que la violencia queda superada. ${ }^{16}$

Pero estas ideas teleológicas son justamente la parte más vulnerable de la concepción hegeliana, y lo que ha pervivido en nuestro siglo es sobre todo la idea de la violencia y la lucha como factor esencial de la historia y del movimiento en general; la violencia como "partera de la historia" - según dijo Marx-. Particularmente, en Sartre la violencia es absoluta e insuperable, como lo es el reino de la escasez en que ella se inscribe; la violencia interhumana, que no tiene conciliación ni pacificación posibles, constituye, en efecto, la idea central tanto de su ontología del hombre como de su explicación dialéctica de la historia.

15 Eduardo Nicol, El porvenir de la filosofia, F. C. E., México, 1972; p. 50. Podria añadirse que universalizada, "normalizada", constante y casi invisible, la violencia se da, paradojicamente, como algo en apariencia "no violento": de ahi su mayor inconsciencia, peligrosidad y acción corrosiva.

16 Cf. Eugenio Trias, El lenguaje del perdón; Ed. Anagrama, Barcelona. 
La verdad, para Sartre, es el Terror. Su dialéctica lleva hasta las últimas consecuencias el momento antitético hegeliano sin posibilidad de síntesis o armonía, ni siquiera en el más utópico futuro o telos de la historia; los contrarios, sean aquí individuos o grupos, son necesariamente excluyentes entre sí y en esta exclusión o lucha sin fin habria de consistir la "razón dialéctica":

El hombre es violento, en toda la Historia y hasta nuestros dias... contra su Hermano, en tanto que éste tiene la posibilidad permanente de convertirse en contra-hombre. ${ }^{17}$

Aparte de otras cuestiones aquí contenidas, es indispensable advertir ahora que este sentido ontológico de la violencia (además de que confirma y refuerza, en el orden teórico, la universalización de la violencia que se produce en el orden práctico) remite de manera directa a otro de los grandes problemas que plantea el fenómeno de la violencia: el de si esta violencia -entendida en su significación negativa, como principio de lucha interhumana e incluso de destrucción o literal aniquilaciónes inherente al hombre, constitutiva, universal y necesariamente, y por tanto, no susceptible de ser superada, ni ética ni históricamente.

Pero antes de abordar esta última cuestión, quizá pudieran formularse algunas posibles conclusiones:

1ạ: Aun tomándose en cuenta su ambivalencia (su analogia con las dos gotas de sangre de Gorgona), la violencia parece tener una significación predominantemente negativa: la violencia en sentido estricto es fuerza de odio y destructividad, con características cercanas a las que Freud atribuye a las pulsiones de muerte, la repetición, la disolución, la agresión interna y externa.

2a: Si por el contrario, se habla de "buena violencia", ésta parece tener en realidad una de las tres siguientes significaciones:

a) es más bien fuerza, lucha, poder o potencia, en el sentido más amplio de estos términos: energia vital, expansiva, liberadora, creadora, verdaderamente revolucionaria y no propiamente "violencia".

b) o si es violencia en sentido estricto (negativa: sangrienta, destructora), $y$ adquiere una significación positiva, es "buena violencia", pero únicamente por el contexto vital en que se inscribe, por la función estructural que cumple; no sólo como un medio para un fin positivo o

17 Jean Paul Sartre, Critique de la raison dialectique, Gallimard, Paris, 1960; p. 689. Cf. asimismo, R. D. Laing y D. G. Cooper, Razón y violencia, Paidós, B. Aires, 1973. 
como un mal menor, sino con todas las restricciones señaladas: como último recurso, parcial, relativizado, pasajero, contingente, controlado, excepcional, autoconsciente, desplazado y minimizado al máximo posible. No pierde su carácter de violencia (negativa), pero queda restringida. Lo "bueno" o "justificado" no es tampoco en este caso la violencia como tal, sino el contexto positivo, en que se inscribe.

c) o bien, no es ni positiva ni negativa, sino que se trata de la violencia como un fenómeno necesario, de fuerza mayor, que no cabe propiamente cualificarse como "bueno" o "malo", "legitimo" o "ilegitimo", sino que es neutral, descualificado y queda mejor designado como simple agresividad biológica destinada a la conservación de la vida, y cuya neutralidad es la medida de su pertenencia al orden puramente natural.

La agresividad en este sentido es un fenómeno vital, racional, destinado a la sobrevivencia, esencialmente útil para la vida, muy lejano en sí a los excesos y deformaciones irracionales de la hybris humana, de la crueldad, la represión, la destrucción intraespecifica, la malignidad de la violencia propia del hombre. ${ }^{18}$ Se trata en general, más que de violencia en sentido estricto, de la fuerza imperante o potencia de la Naturaleza, la vis o la Bias a las que se aludía antes.

La cuestión es entonces determinar si concebida en su sentido estricto de violencia negativa o mala violencia, como expresión de odio, destructividad, furia sangrienta, mal, etcétera, se trata de un fenómeno innato, inherente a la naturaleza humana - y por ende universal e insuperableo si, por el contrario, es un hecho sociocultural, históricamente transitorio y susceptible de transformación.

El problema se ha solido plantear en términos dualistas o de un antagonismo entre naturaleza y cultura (entre lo constitutivo-permanente y lo histórico-cambiante). Asi, unos insisten en esa naturaleza violenta y maligna del ser humano: "el hombre lobo del hombre"; o sea, en el carácter necesario e inmutable de la violencia. Otros, por el contrario, sostienen que el mal no proviene de ninguna naturaleza o esencia humana; que tiene su origen en la cultura, en las instituciones de explotación, de destructividad y de violencia misma que han sido creadas milenariamente por la sociedad; es la propia sociedad, por tanto, la responsable del mal y la violencia, y la que también es capaz de transformar ese "estado de cosas" supuestamente natural e inalterable. Aseguran en suma, que es más bien por naturaleza que el hombre cuenta con un impulso originario y esencial de perseverar en el ser -como lo formuló Spinoza—, de afirmar la vida, la paz y la racionalidad.

18 Cf. Erich Fromm, Anatomia de la destructividad humana, Siglo XXI Ed., México, 1975. 
Sin embargo, si se comienza por partir de la orginaria e indisoluble unidad "psicosomática" que revela lo humano, de la integración efectiva de "naturaleza" y "cultura", "materia" e "historia" (y por tanto, de la implicación de necesidad y contingencia, permanencia y cambio, determinación y libertad, etcétera), entonces el problema no es tan simple ni unilateral.

La violencia -como todos los "males" y todos los "bienes"- no proviene de "afuera" ni de "arriba": de algo extraño, opuesto a la naturaleza física y a la materia, o ajeno (ontológica, metafísicamente) al ser propio del hombre o a su propia "esencia". "Bien" y "mal" tienen un origen y un sustrato "terrenal", vital, humano, e incluso pulsional: no son ni divinos ni satánicos. En este sentido, la violencia - que es de lo que aquí se trata- tiene, sí, algo de connatural, universal e inextirpable. Hay verdad, en efecto, en ese hallazgo freudiano de una especie de "fondo" del fondo mismo que son las pulsiones de muerte y agresividad [Thd́natos], tanto más originarias y determinantes, según él, que las pulsiones libidinales o de vida [Eros]. Pero también es cierto que, en otro sentido, toda condición pulsional se halla en las fronteras mismas de lo psíquico y lo orgánico y que no se trata propiamente de naturaleza o instinto como algo absolutamente necesario y uniforme, ajeno a la acción histórica, moral y cultural.

En términos ontológicos, se trata de una condición potencial (ser en potencia) que conlleva su propio margen de indeterminación, que tiene carácter posible y no necesario y que implica en sí mismo la alternativa, la ambigüedad y la contradicción. Las pulsiones humanas son contrarias, pueden ser o no ser, ejercerse así o de otro modo, servir a la vida o a la muerte, desbordarse o frustrarse, vincular o separar, construir o destruir: son alternativa permanente, condición posible y por ello cualificable..$^{18}$

Es esta condición humana potencial y contradictoria, natural y cultural a la vez, la que explica que la vis - la fuerza humana, e incluso la violencia en sentido amplio- pueda ser tanto potencia vital, expansiva y liberadora, como poder excesivo y excedido, hybris desbordada y desencadenada que revierte en ruina, en opresión y destrucción; o que, por el contrario, que quede frustrada, inhibida y se manifieste en todas

19 "...en la vida animal -como observa Girard- la violencia está dotada de frenos individuales. Los animales de una misma especie jamás se enfrentan hasta la muerte; el vencedor perdona al vencido. La especie humana está desprovista de esta protección. El mecanismo biológico individual es sustituido por el mecanismo colectivo y cultural de la victima propiciatoria... sin religión ninguna sociedad sería posible", op. cit., p. 227. Cf., asimismo: K. Lorenz, Sobre la agresión, el pretendido mal, Siglo XXI ed., México, 1971. 
las otras modalidades negativas de la violencia, expresivas no de poder, sino de impotencia.

Todas estas posibles direcciones de la fuerza y la violencia son a la vez "necesidad" y "libertad"; están determinadas en cada situación concreta, individual y colectiva; pesan como una especie de fatalidad; de naturaleza "dada", para bien o para mal: como "destino" que parece inalterable y que rebasa nuestra propia voluntad. Pero al mismo tiempo, por su propia y encontrada diversidad, por su condición contingente y no necesaria, por el margen de indeterminación que siempre contienen, son esencialmente libres: responsabilidad ética e histórica del hombre; son tarea cultural (cultivo) y no mero desenlace natural, forzoso y uniforme: son acción humana (praxis, póiesis, techné).

Acaso las pulsiones de muerte y la violencia nociva sean en principio más poderosas, tengan más fuerza de necesidad, sean más "naturales" y generalizadas $\mathrm{y}$, sobre todo, más fáciles de emerger y más frecuentemente realizadas, mientras que la fuerza de la paz, de la razón, de la virtud, de la conciliación, de la creatividad, del Eros, sea obra de la decisión y del esfuerzo libre, innovador y constructor del hombre: de ahi su dificultad, su rareza, su fragilidad y su riesgo. Quizá por tener una raíz natural - por ser pulsional e incluso constitutiva, la violencia en cuanto tal, la mala violencia - nunca se pueda exterminar y no sobrevenga jamás el estático reino de la mansedumbre, la templanza y la reconcilia. ción absolutas. Ello es congruente con nuestra relatividad y nuestra humanidad: siempre histórica, siempre ética.

Pero acaso también -y por eso mismo - el hombre pueda, tenga "en potencia" el poder (porque tiene el impulso, la pulsión vital) de producir transformaciones esenciales en su ser ético y en su ser histórico, y revolucione verdaderamente sus propias estructuras existenciales, de modo que la violencia y la malignidad, la destructividad y la esclavitud dejen de ser hegemónicas, queden desplazadas, bajo control, parcializadas, trascendidas dentro de un contexto mayor en el que se ejerzan las otras fuerzas de vitalidad, liberación y comunicación, de interioridad y creatividad; un contexto en el que se exprese, como una opción para todos, la genuina riqueza y variedad de las potencialidades humanas, que son más, mucho más que la simple violencia explosiva; donde la hegemonia, en definitiva, la obtenga ese pacifismo casi "instintivo", "orgánico", espontáneo y connatural (al que se refería el propio Freud en su correspondencia con Einstein) y puedan, desde él, ejercerse también predominantemente los poderes esenciales de la no violencia, la racionalidad y la humanización. 